\title{
CORRELATION OF RECTOCOELE SYMPTOMATOLOGY WITH PELVIC ORGAN PROLAPSE QUANTIFICATION MEASUREMENT
}

\author{
Hemant Deshpande1, Chandrakant Madkar², Shefali Gupta ${ }^{3}$, Rajendra Shitole ${ }^{4}$, Yogesh Trivedi ${ }^{5}$ \\ 1 Professor \& HOD, Department of Obstetrics \& Gynaecology, Dr. D. Y. Patil Medical College, Pimpri, Pune. \\ 2Professor, Department of Obstetrics \& Gynaecology, Dr. D. Y. Patil Medical College, Pimpri, Pune. \\ ${ }_{33}^{\text {rd }}$ Year Junior Resident, Department of Obstetrics \& Gynaecology, Dr. D. Y. Patil Medical College, Pimpri, Pune. \\ ${ }^{4}$ Senior Resident, Department of Obstetrics \& Gynaecology, Dr. D. Y. Patil Medical College, Pimpri, Pune. \\ ${ }_{5}^{5}$ Senior Resident, Department of Obstetrics \& Gynaecology, Dr. D. Y. Patil Medical College, Pimpri, Pune.
}

\section{ABSTRACT}

\section{BACKGROUND}

The newly introduced pelvic organ prolapse quantification (POPQ) classification by International Continence Society [ICS in 1996] has been found to be definitely superior to old classification. The main difference between old and new classification is that the new classification is able to give us accurate measurement in $\mathrm{cm}$ as opposed to old classification which was vague, nonspecific and inaccurate. Obviously, POPQ classification is much useful in academic and research studies because we are able to apply test of statistical significance due to specific measurement in POPQ staging. In this study, we are focusing on one aspect of POP that is rectocoele where we will study about symptomatic relations of the rectocoele with the POPQ measurement.

Objective of this study is to evaluate symptoms of rectocoele in relation to POPQ measurement.

\section{MATERIALS AND METHODS}

This is a prospective study of 100 patients coming to our hospital with finding suggestive of rectocoele symptoms and signs. Details of symptomatology was studied with measurement of posterior vaginal wall prolapse in $\mathrm{cm}$. All the data is collected and analysed to know about the statistical significance of the various measurements.

\section{RESULTS}

In our study, we found that the symptoms of rectocoele are correlated with POPQ measurements and found to be statistically significant showing increased severity as the measurement of POPQ component increases.

\section{CONCLUSION}

Our study has been possible only due to POPQ classification measurement which has been specifically designed for the purpose of research where specific and accurate findings are required.

\section{KEYWORDS}

Pelvic Organ Prolapse (POP), Pelvic Organ Prolapse Quantification (POPQ), Rectocoele, Symptomatology, Simplified Pelvic Organ Prolapse Scoring System, Manual Correction of Rectocoele.

HOW TO CITE THIS ARTICLE: Deshpande H, Madkar C, Gupta S, et al. Correlation of rectocoele symptomatology with pelvic organ prolapse quantification measurement. J. Evolution Med. Dent. Sci. 2017;6(3):210-214, DOI: 10.14260/Jemds/2017/49

\section{BACKGROUND}

A rectocoele is an outpocketing of the anterior rectal and posterior vaginal wall into the lumen of the vagina. ${ }^{1}$ Some rectocoeles may be asymptomatic whereas others may cause symptoms of incomplete bowel emptying, vaginal mass, pain and pressure. ${ }^{2}$ The genital prolapse is age old entity and has been described in oldest documented medical literature like Egyptian papyri [Kahun papyri circa 1835 BCE]. In fact, it is the most common problem found in the patient attending gynaecology. POP is defined as downward displacement of uterus, cervix and vaginal wall with surrounding structures

Financial or Other, Competing Interest: None.

Submission 02-12-2016, Peer Review 24-12-2016,

Acceptance 02-01-2017, Published 09-01-2017.

Corresponding Author:

Dr. Shefali Gupta,

Room No. A(06),

Dr. D. Y. Patil Old Girls Hostel,

Sant Tukaram Nagar, Pimpri, Pune.

E-mail: drgupta.shefali211@gmail.com

DOI: $10.14260 /$ jemds $/ 2017 / 49$ like bladder, urethra, bowel and rectum from their normal anatomical positions and in severe cases, patient will complain of mass coming out of vagina because of protrusion of structure outside the introitus.

The incidence of rectocoeles is $20-80 \%$ in the general population and is thought to be increasing. ${ }^{3}$ It is estimated to affect approximately $50 \%$ of parous women. POP markedly affects a patient's quality of life. ${ }^{4}$

The other structures apart from genital organs are most commonly cystocoeles, rectocoeles, enterocoeles and urethrocoeles; reflecting displacement of the bladder, rectum, small bowel, and urethra respectively; resulting from failure of the endopelvic connective tissue, levator ani muscular support or both.

Rectocoeles result from defects in the integrity of the rectovaginal septum and herniation of the rectal wall into the vaginal lumen. ${ }^{5}$ It results from weakness in the muscular wall of the rectum and the paravaginal musculoconnective tissue, which holds the rectum in place. Pelvic organ prolapse is a bulge or protrusion of pelvic organs and their associated vaginal segments into or through the vagina. 


\section{Classification}

Various classifications have been described. According to one scheme, three degrees of uterine descent are recognised.

\section{First Degree}

Descent of the uterus but the cervix remains within the introitus.

\section{Second Degree}

Descent to the extent that the cervix projects through the vulva when the woman is straining or standing.

\section{Third Degree}

Complete procidentia or general prolapse: The entire uterus prolapses outside the vulva. The whole vagina or at least the whole of its anterior wall is everted.

In Shaw's classification, descent is classified into four degrees - the first degree remains the same as above, but second degree is one where the cervix descends to the level of the introitus; the third when it projects through the vulva; and the fourth degree is complete procidentia.

Baden's system of grading is similar to Shaw's but uses the hymen as a reference point. Each component is graded from 0 to 4 with the patient straining.

\section{Urethrocoele, Cystocoele, Prolapse, Rectocoele}

0 Normal.

1 Descent to halfway to hymen.

2 Progression to hymen.

3 Progression halfway through hymen.

4 Maximal progression through hymen.

\section{Enterocoele}

0 Normal. Maximum of $2 \mathrm{~cm}$ of cul-de-sac between posterior cervix and rectum.

1 Herniation of cul-de-sac to one-fourth of distance to hymen.

2 Herniation to two-fourths of distance towards hymen.

3 Herniation to three-fourths of distance towards hymen.

4 Herniation to hymen.

\section{Chronic Perineal Laceration}

0 Normal (no more than hymenal laceration).

1 Involvement of anterior half of perineal body.

2 Involvement of perineal body but not anal sphincter.

3 Involvement including anal sphincter.

4 Involvement including anal mucosa.

(However, these systems do not provide accurate quantification for scientific comparison, lack reproducibility and specificity and may not accurately describe the structures associated with the sites of prolapse). To overcome the lacunae in above classification, the International Continence Society has therefore approved a new system, the Pelvic Organ Prolapse Quantification (POPQ) staging system, which measures in centimetres the positions of 9 sites on the vagina and perineal body in relation to the hymen. (Figure 1 and 2 ).

\section{These 9 Sites are as follows}

Aa- Located $3 \mathrm{~cm}$ proximal to the urethral meatus on the anterior vaginal wall;
Ba- The most distal position of the upper anterior wall;

C- The most distal edge of the cervix or vaginal cuff;

D- The location of the posterior vaginal fornix;

Ap- Located $3 \mathrm{~cm}$ proximal to the hymen on the posterior vaginal wall;

Bp- The most distal position of the upper portion of the posterior vaginal wall.

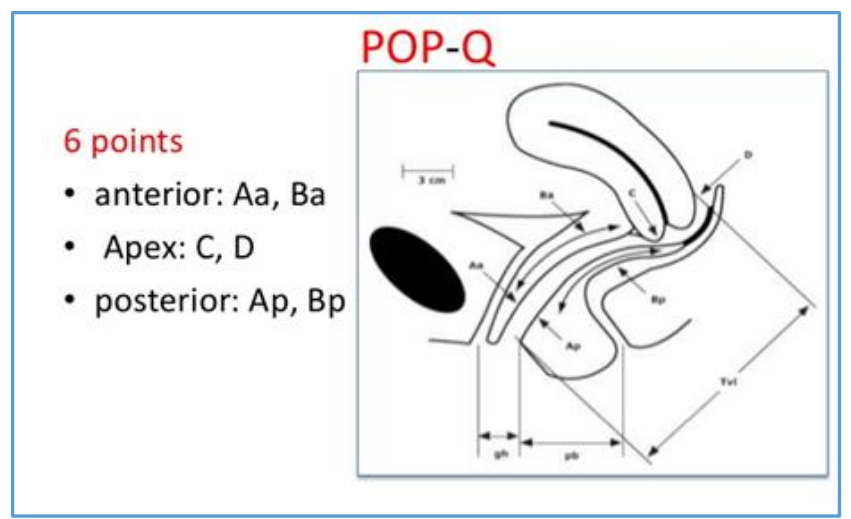

Figure 1

In addition, the diameter of the genital hiatus (gh), width of the perineal body (pb), and the total vaginal length (tvl) are measured and recorded on a grid form (Fig 2). A final prolapse stage from 0 to 4 can be assigned according the severity of the greatest degree of prolapse.

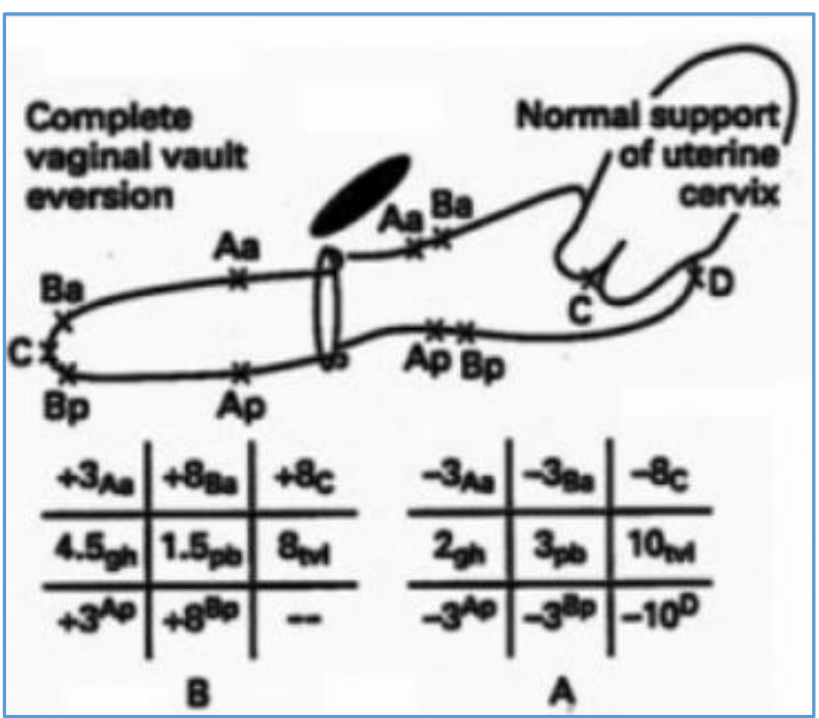

Figure 2

It is important to recognise that these measurements can change according to the position of the patient e.g. standing or lithotomy and by insertion of a speculum. It is also important to mention whether the patient was straining or whether traction was applied. Measurements at points gh and pb are completed first. A speculum is then placed in the vagina to allow introduction of a spatula and measurement of tvl. Points $\mathrm{C}$ and $\mathrm{D}$ are next measured during maximal Valsalva effort. Lastly, points $\mathrm{Aa}, \mathrm{Ba}, \mathrm{Ap}$ and $\mathrm{Bp}$ are measured. ${ }^{6}$ The new classification has been prepared and simplified Pelvic Organ Prolapse Scoring system to make the things simple. ${ }^{7}$ However, they have specifically mentioned that it is not useful for research purpose for which the 
standard POP classification is recommended, so we have used the standard classification.

Our study is mainly focusing on rectocoele. Although rectocoele is common, associated symptoms are widely variable. Rectocoele results from defects in the integrity of rectovaginal septum and herniation of rectal wall into the vaginal lumen. According to the level of location of weakness in recto-vaginal septum, it can be classified as proximal [high], medial [mid-vaginal] and distal [low].

In some cases, the perineal body may become distended and lose its bulk leading to a perineocoele which can be only diagnosed on digital rectal examination.

\section{Aetiology}

Rectocoeles were previously thought to be a condition affecting only multiparous women. More recently, rectocoeles and enterocoeles were noted to occur in approximately $40 \%$ asymptomatic parous women. ${ }^{8}$ Sharvon and Colleagues performed defecography on healthy, young, nulliparous, asymptomatic volunteers noting 17 of 21 women had small or moderate-sized rectocoeles. ${ }^{9}$ Rectocoele and other forms of POP are the result of women attaining an erect bipedal posture. Aetiologically, most cases are the result of vaginal childbirth and chronic increases in intra-abdominal pressure [such as chronic constipation]. In some patients, rectocoele is thought to develop as a result of congenital or inherited weaknesses within the pelvic support system.

\section{Clinical Presentation}

A common complaint is constipation, which may occur in $75 \%$ of women with rectocoeles. Patients may complain of incomplete rectal emptying, a sense of rectal pressure, or a vaginal bulge. ${ }^{10}$ Vaginal manipulation is sometimes necessary to facilitate defecation. ${ }^{11}$

\section{Anatomy}

As rectocoele is totally related to posterior vaginal wall, to have basic understanding, one must be clear about supports of vagina. The supports of vagina are found to be as three levels due to which vagina is stabilised. Superiorly, the vaginal apical endopelvic fascia is attached to the cardinaluterosacral ligament complex. Laterally, the endopelvic fascia is connected to the arcus tendineus fasciae pelvis, with the lateral posterior vagina attaching to the fascia overlying the levator ani muscles. Inferiorly, the lower, posterior vagina connects to the perineal body. ${ }^{12}$

The anterior wall of the rectum and the posterior vaginal wall are fused for approximately 3 to $4 \mathrm{~cm}$ into the vagina. Evaluation of posterior vaginal wall defects requires not only an anatomical description of the prolapse, but also correlation of any functional derangements that may exist. Evaluation may include defecography, bowel transit studies, ultrasound and magnetic resonance imaging. ${ }^{13}$ Defecography is recommended as a helpful diagnostic tool in the work-up of patients with posterior vaginal wall prolapse if surgical repair is considered. ${ }^{14}$

\section{MATERIALS AND METHODS}

This was a single institution based, prospective and observational study in which permission of ethical committee and informed consent of the patient for participation of study were taken.
The detail genital examination was done after emptying bladder in lithotomy position by using a standard POPQ technique with the help of POPQ stick showing measurement in $\mathrm{cm}$ as shown in figure 3 . At the same time, the grade of prolapse was noted according to previous classification.

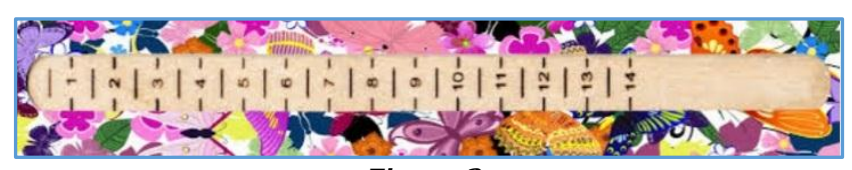

Figure 3

In our study, we included 100 patients coming to our obstetrics and gynaecology OPD in our institution.

Our study was specifically focusing on the rectocoele symptomatology as seen in figure 4 .

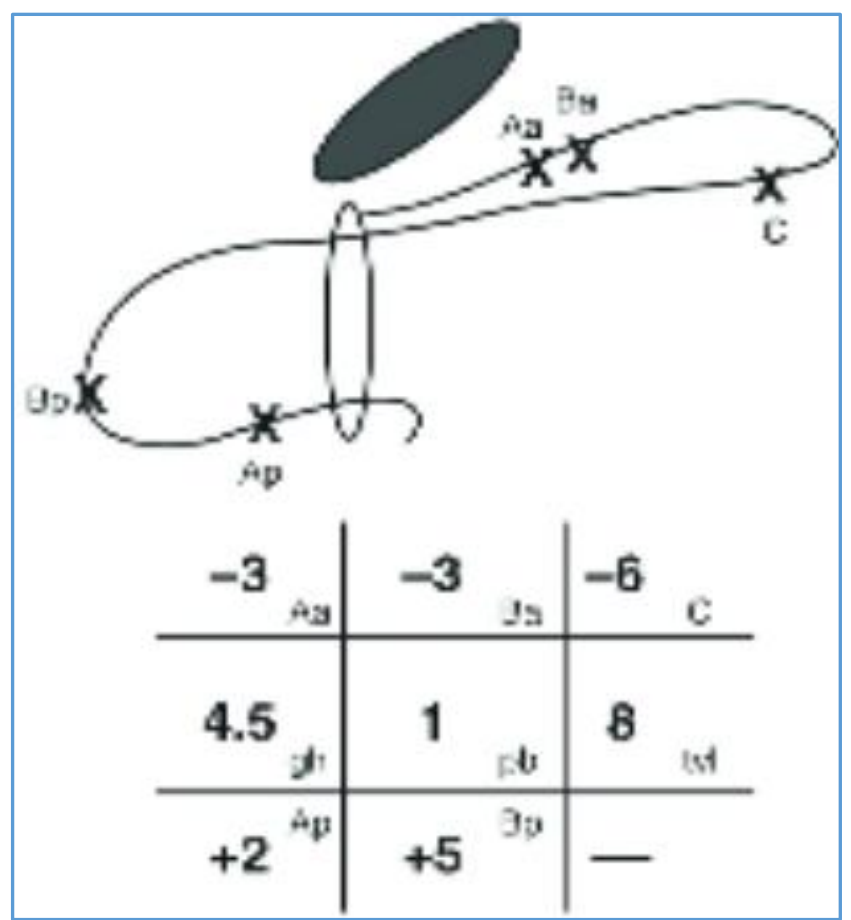

Figure 4

Depending on the level of weakness in the support of the posterior vaginal wall, rectocoele can be three types - high, mid and low (Figure 4) as the posterior vaginal wall prolapse at low level can have mixed contents that is anal canal and rectum which is called as ano-rectocoele. Similarly, herniation through perineum can also occur which is called as perineocoele. Due the this anatomical variation, presentation of the symptoms can be different from typical rectocoele shown in figure no. 3 which occurs through midvaginal portion as seen in this figure 5 , so we have excluded the patients of ano-rectocoele and perineocoele and taken displacement of point Bp for the comparison of symptoms. Few studies which have been done on this topic have also considered the same things. ${ }^{15}$ 


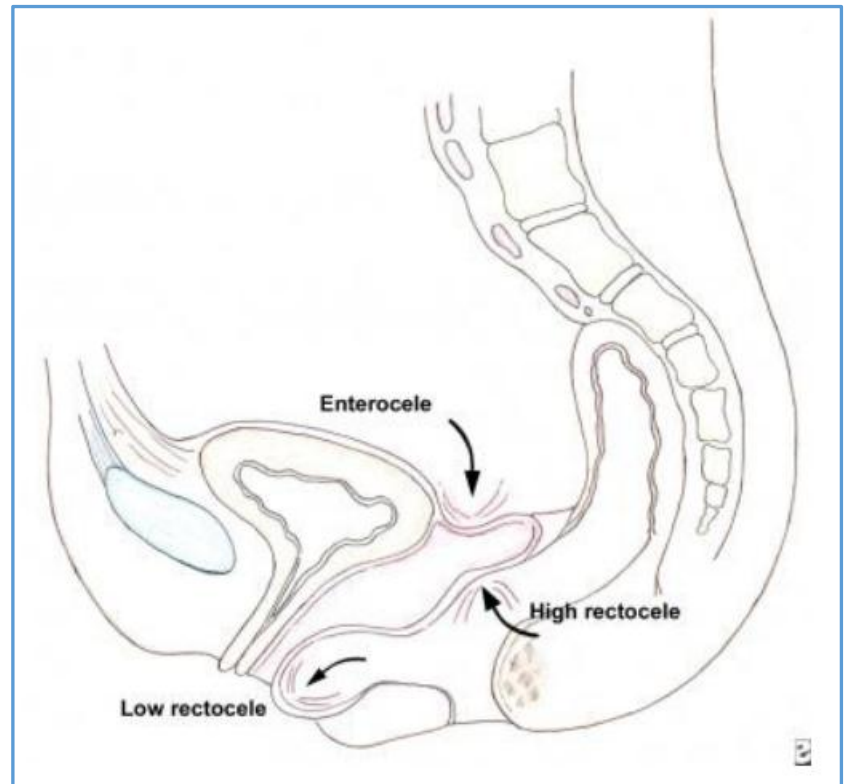

RESULTS

Figure 5

\begin{tabular}{|c|c|c|}
\hline Complaints & Number of Cases & Percentage \\
\hline $\begin{array}{c}\text { Something coming } \\
\text { out of vagina (bulge) }\end{array}$ & 28 & 28 \\
\hline Constipation & 50 & 50 \\
\hline $\begin{array}{c}\text { Manual correction of } \\
\text { rectocoele }\end{array}$ & 23 & 23 \\
\hline Asymptomatic & 35 & 35 \\
\hline \multicolumn{2}{|c|}{ Table 1. Analysis of Rectocoele Complaints } \\
\hline
\end{tabular}

(Some patients having more than one symptom).

Constipation was found to be $50 \%$ in our study. Actually, it can be etiological factor of prolapse or prolapse can cause constipation due to the impaction of faecal material. The complaint of something coming out of vagina was found in 28 patients in whom $\mathrm{Bp}$ was +1 and more suggesting that the threshold for this complaint is $\mathrm{Bp}$ at +1 .

Statistical results and details about the symptoms have been given in following tables.

\begin{tabular}{|c|c|c|c|c|c|c|c|}
\hline POPQ & $\begin{array}{c}\text { Bp } \\
\mathbf{( - 3})\end{array}$ & $\begin{array}{c}\text { Bp } \\
\mathbf{( - 2})\end{array}$ & $\begin{array}{c}\text { Bp } \\
\mathbf{( - 1 )}\end{array}$ & $\begin{array}{c}\text { Bp } \\
\mathbf{( 0 )}\end{array}$ & $\begin{array}{c}\text { Bp } \\
\mathbf{( + 1 )}\end{array}$ & $\begin{array}{c}\text { Bp } \\
\mathbf{( + 2 ~ \& ~} \\
\text { More })\end{array}$ & Total \\
\hline $\begin{array}{c}\text { Consti } \\
\text { pation }\end{array}$ & 1 & 2 & 6 & 13 & 19 & 9 & 50 \\
\hline
\end{tabular}

\begin{tabular}{|c|c|c|c|}
\hline POPQ - 2a & Bp (-3) & Bp (-2) & Bp (-1) \\
\hline No. of pts. & 1 & 2 & 6 \\
\hline Percentage & 33.33 & 33.33 & 60 \\
\hline
\end{tabular}

\begin{tabular}{|c|c|c|c|}
\hline POPQ - 2b & Bp(0) & Bp(+1) & Bp(+2) or More \\
\hline No. of pts. & 13 & 19 & 9 \\
\hline Percentage & 86.66 & 90 & 90 \\
\hline \multicolumn{5}{|c|}{ Table 2. Analysis of Patients with Symptoms of } \\
Constipation with POPQ component Bp \\
\hline
\end{tabular}

Fisher Exact probability test: $\mathrm{p}$ value: 0.0428 significant $\mathrm{p}$ value: $<0.05$.

Percentage of patients increases along with increase in value of POPQ component $B p$.

Table suggests that $p$ value is statistically significant.

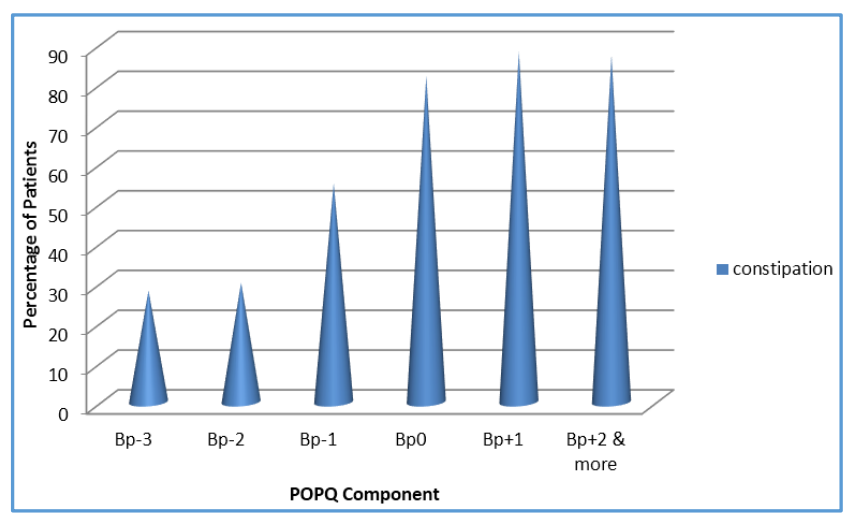

Graph 1: Analysis of Patients with Symptoms of Constipation with $P O P Q$ component Bp

\begin{tabular}{|c|c|c|c|c|c|c|c|}
\hline POPQ & $\begin{array}{c}\text { Bp } \\
\mathbf{( - 3 )}\end{array}$ & $\begin{array}{c}\text { Bp } \\
\mathbf{( - 2 )}\end{array}$ & $\begin{array}{c}\text { Bp } \\
\mathbf{( - 1 )}\end{array}$ & $\begin{array}{c}\text { Bp } \\
\mathbf{( 0 )}\end{array}$ & $\begin{array}{c}\text { Bp } \\
\mathbf{( + 1 )}\end{array}$ & $\begin{array}{c}\text { Bp } \\
\mathbf{( + 2} \boldsymbol{\&} \\
\text { More }\end{array}$ & Total \\
\hline $\begin{array}{c}\text { Manual } \\
\text { correction in } \\
\text { rectocoele }\end{array}$ & 0 & 0 & 3 & 5 & 10 & 5 & 23 \\
\hline
\end{tabular}

\begin{tabular}{|c|c|c|c|}
\hline POPQ - 3a & Bp (-3) & Bp (-2) & Bp (-1) \\
\hline No. of pts. & 0 & 0 & 3 \\
\hline Percentage & 0 & 0 & 30 \\
\hline
\end{tabular}

\begin{tabular}{|c|c|c|c|}
\hline POPQ - 3b & Bp (0) & Bp (+1) & Bp (+2 or more) \\
\hline No. of pts. & 5 & 10 & 5 \\
\hline Percentage & 33.33 & 47.62 & 50 \\
\hline \multicolumn{3}{|c|}{ Table 3. Relation between POPQ component } \\
Bp and Manual correction in Rectocoele \\
\hline
\end{tabular}

Fisher Exact probability test: p value: 0.03727 , Significant, $\mathrm{p}$ value: $<0.05$.

Percentage of patients increases along with increase in value of POPQ component Bp.

Table 3 shows that manual correction is required more as POPQ component Bp increases.

$P$ value suggests it is statistically significant.

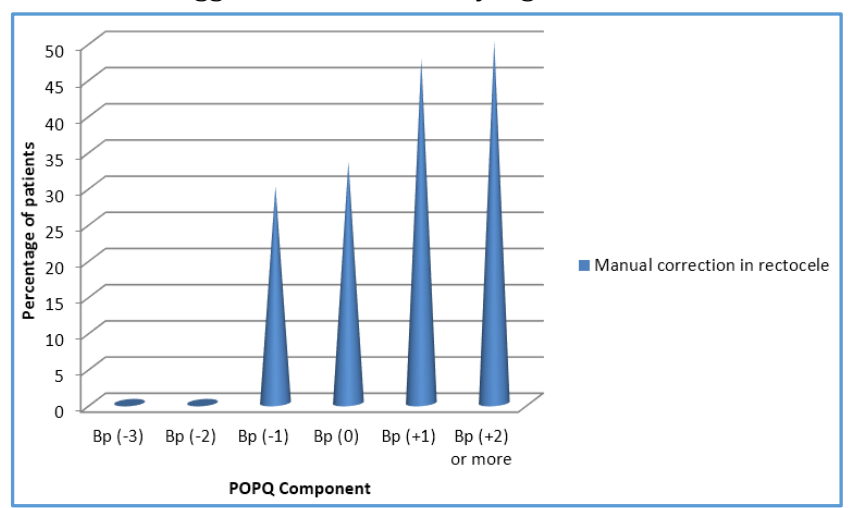

Graph 2. Relation between POPQ component and Manual correction in Rectocoele 
In our study, we are focusing on three symptoms that is something coming out of vagina (bulge), constipation and manual correction of rectocoele.

\section{DISCUSSION}

Before the invention of POPQ classification, it was vague description of the symptoms, correlation with the size of rectocoele like large rectocoele causes more problem as opposed to the small rectocoele or there is no correlation of symptoms with the size. Nothing was defined about the dimensions of large and small rectocoeles. According to the classification, we are able to take accurate measurement with the help of graduated stick having marking in $\mathrm{cm}$, so that we have been able to know the extent of severity of the symptoms in relation to measurement. Our data analysis has been shown clear-cut correlation about symptomatology and POPQ measurement due to same. We have been able to apply test of statistical significance to confirm our finding and able to come to definite conclusion. Our study is showing increase in severity along with the increase in measurement. We have applied Fisher test for the same.

This is the purpose of innovative new classification which is very specific and accurate and helpful for research purpose and also got other advantages like elimination of personal errors in the inter-observational study. It is also helpful in evaluation of patients in post-operative period.

We had 100 patients for above study, it shows that $50 \%$ patients had complaints of constipation while $23 \%$ patients had complaints of requirement of manual correction to pass stool. Some had more than one complaint.

By Fisher Exact Probability Test, we found $p$ value is statistically significant.

This type of study which correlates clinically with measurement of prolapse in centimetres as per POPQ classification is possible by POPQ method only and not possible by old methods.

\section{CONCLUSION}

It is clearly seen from our study that the severity of symptoms of rectocoele are increasing with POPQ measurement. It should also be noted that the previous classifications were nonspecific and inaccurate due to lack of measurement in $\mathrm{cm}$ which is a major correction in the POPQ classification. We think that every gynaecologist should practise prolapse status by POPQ measurement and its record should be maintained. More studies on large sample should be done before coming to final conclusion.

\section{REFERENCES}

[1] Mellgren A, Anzen B, Nilsson BY, et al. Results of rectocoele repair. A prospective study. Dis Colon Rectum 1995;38(1):7-13.
[2] Porter WE, Summitt RL, Women's med. The pathophysiology, diagnosis and management of rectocoeles. GLOWM 2008;6:10058.

[3] Mollen RMHG, van Lurrhoven JHM, Kuijpers JHC. Pathogenesis and management of rectocoeles. Semin Colorectal Surg 1996;7:192.

[4] Narwadkar M, Sarode P. Recent innovations in management of pelvic organ prolapse. AICOG obstetrics and gynecology update 2016.

[5] Pollak J, Davila GW. Rectocoele repair: the gynaecologic approach. Clin Colon Rectal Surg 2003;16(1):61-70.

[6] Kumar P, Malhotra N, Malhotra J, et al. Pelvic organ prolapse. Jeffcoate's Principles of gynaecology. $8^{\text {th }}$ edn. 2014:252-4.

[7] Nivedita R, Pratima M, Jyotsna S, et al. Comparative study to evaluate the intersystem association and reliability between standard POPQ system and simplified POP scoring system. Journal of Obstetrics and Gynecology of India 2014;64(6):421-4.

[8] Walters MD. Pelvic floor prolapse: cystocoele and rectocoele. In: Walters MD, Karram MM. eds. Clinical urogynecology. St. Louis: Mosby-Year book 1993:22536.

[9] Shorvon PJ, McHugh S, Diamant NE, et al. Defecography in normal volunteers: results and implications. Gut 1989;30(12):1737-49.

[10] Murthy VK, Orkin BA, Smith LE, et al. Excellent outcome using selective criteria for rectocoele repair. Dis Colon Rectum. 1996;39(4):374-8.

[11] Karlbom U, Graf W, Nilsson S, et al. Does surgical repair of a rectocoele improve rectal emptying? Dis Colon Rectum 1996;39(11):1296-302.

[12] DeLancy J0. Anatomic aspects of vaginal eversion after hysterectomy. Am J Obstet Gynecol 1992;166(6 Pt 1):1717-28.

[13] Kleeman SD, Karram M. Posterior pelvic floor prolapse and a review of the anatomy, preoperative testing and surgical management. Minerva Ginecol 2008;60(2):165-82.

[14] Groenendijk AG, van der Hulst VP, Birnie E, et al. Correlation between posterior vaginal wall defects assessed by clinical examination and by defecography. Int Urogynecol J Pelvic Floor Dysfunct 2008;19(9):1291-7.

[15] Sarah CA, O'Sullivan DM, Christine LA. Correlation of POP-Q posterior compartment measures with defecatory dysfunction. International Urogynecology Journal 2012;23(6):743-7. 